\title{
LA INFLUENCIA DEL ARQUETIPO DE LA GRAN MADRE EN EL BULLYING A TRAVÉS DE CARRIE $^{1}$ (1974) DE STEPHEN KING
}

\author{
MARTA G. MORENO
}

Recibido 13-01-2015

Aceptado 27-04-2015

\section{Resumen}

Los arquetipos del inconsciente colectivo ponen al descubierto ciertos complejos que subyacen en la psique y que son proyectados por esta. La adolescencia es un momento crucial, en el que un entorno familiar inapropiado en contra de su desarrollo social, puede traer unas consecuencias nefastas en el progreso psicológico del adolescente. La literatura, como reflejo de nuestras vivencias, es de nuevo una herramienta de análisis relevante con la que poder exponer cómo el matriarcado puede dificultar el desarrollo normal en la etapa adolescente. A través de la psicología analítica y la simbología de los arquetipos, relacionaremos el arquetipo de la Gran Madre y la influencia en la víctima de bullying. La novela Carrie (1974) nos ayudará a ilustrar tales cuestiones y a explicar cómo estas experiencias son asimiladas por la psique.

Palabras clave: bullying, arquetipos, adolescencia, Gran Madre.

\begin{abstract}
The archetypes from the collective unconscious reveal some complexes that lie beneath the psyche and which are projected by it. Adolescence is a crucial moment when an inappropriate family environmental against its social development, it can suppose terrible consequences in the psychological development of the adolescent. Literature, as a reflection of our life experiences, is again a relevant analysis tool to explain, how matriarchy, can complicate a normal stage of development in adolescence. Through analytical psychology, the symbology of the archetypes will relate the Great
\end{abstract}

1. KING, Stephen. «Carrie»: The Shining, Carrie and Misery. Great Britain. Chancelor Press, 1993, pp. 319-439.

Feminismo/s 25, junio 2015, pp. 183-200

DOI: 10.14198/fem.2015.25.10 
Mother archetype and the influence in the bullying victim. Carrie (1974) will help us to explain these questions and how these experiences are assimilated by the psyche.

Keywords: bullying, archetypes, adolescence, Great Mother. 


\section{Introducción}

Es algo desafortunado que la feminidad en la literatura, en términos psicoanalistas, solo sea vista a partir de una lectura crítica freudiana, en la que las teorías de Jung, sin embargo, no han sido tenidas en cuenta con la frecuencia con la que se debiera. De acuerdo con Ortiz-Osés ${ }^{2}$, Jung es, frente a Freud, religioso. El primero de ellos ataca la característica unidimensional del Cristianismo, que, de acuerdo con el psicólogo suizo, creó un Dios todo bondad, perfección y, por supuesto, perteneciente al género masculino, responsabilizando al Ser humano del mal, representado por la Mujer (Eva). No es de extrañar que en diversas proyecciones religioso-profanas, la Trinidad cristiana se complete en Cuaternidad que asume la sombra, o dicho de otra forma, el mal o pecado, bajo la figura de la mater-materia, Eva o la Mujer. Esta explicación no es más que la punta del iceberg de lo que esta idea puede repercutir, no solo en el concepto de los hombres sobre la mujer, sino en el de la mujer sobre su propio género. Por ello, aspectos como los personajes que integran la narrativa de lo gótico y el porqué de su analogía con la mitología, el folclore e incluso aspectos como la religión en su creación, no han sido demasiado atendidos desde el enfoque de la psicología analítica de los arquetipos. En concreto, el conocimiento del arquetipo de lo femenino que se sustrae a partir de las creaciones femeninas de lo inconsciente en su carácter elemental negativo, no solo ha iluminando un nuevo camino sobre los recursos literarios en la narrativa de lo gótico, sino que, además, nos ha dado un enfoque más profundo sobre ciertos clichés que han desembocado en personajes arquetípicos, como ocurre en la obra que nos ocupa.

La forma que tiene de hablarnos el inconsciente es, en ocasiones, a través de las representaciones simbólicas en imágenes. Esto se convierte según Neumann, «en un manantial creativo del espíritu humano» ${ }^{3}$. Así pues, el influjo que el inconsciente deja entrever también se manifiesta en forma de arquetipo, idea que Neumann recoge de palabras de Jung: «Con total independencia

2. ORTIZ-OsÉs, Andrés. Arquetipos y Sentido. Bilbao, Universidad de Deusto, 1988.

3. Neumann, Erich. La Gran Madre: Una fenomenología de las creencias femeninas de lo inconsciente. Madrid, Editorial Trotta, 2009, p. 31. 
de lo que trate de decirnos, todo contenido arquetípico es en principio una metáfora» ${ }^{4}$.

Por ello, el arquetipo nos habla, y lo hace en todos los ámbitos de la cultura. Establece una relación, en este caso con la literatura, que nos permitirá saber el porqué del impacto producido por la novela que nos ocupa. Asimismo, los arquetipos nos darán a conocer el porqué de numerosos comportamientos que nos llevan, en muchos casos, a no poder realizar las pautas establecidas en la sociedad, complicando la integración en la misma. El acoso escolar al que las víctimas se ven sometidas se produce como consecuencia de ambientes familiares desestructurados. Tal y como en el caso que nos ocupa, la educación que recibe la joven Carrie por parte de su madre, produce tal rechazo social, que se convierte en objeto de bullying por parte de sus compañeras de instituto.

En este trabajo analizaremos los rasgos arquetípicos de la Gran Madre en sus diversas representaciones simbólicas, para ver qué relación tienen con la violencia que recibe Carrie, pues este estudio trata de encontrar la raíz del acoso al que se ve sometida la joven en el entorno escolar, categorizando para ello a dos de los personajes femeninos: madre e hija. Las características sustraídas del carácter elemental y transformador de la Gran Madre, Madre Bondadosa y Madre Terrible como un grupo arquetípico homogéneo visto a partir del la fenomenología de las creaciones femeninas de lo inconsciente, serán la base de nuestra metodología. Ello se lleva a cabo en los epígrafes siguientes.

\section{Metodología}

Desde siempre la mujer ha sido considerada un misterio en su naturaleza. Una naturaleza que en ocasiones ha formado más parte de lo mágico que de lo terrenal. La capacidad de dar vida, sus ciclos menstruales etc. Quizás la única manera de comprender lo femenino sea sólo viendo cómo se dirigen y dónde se originan sus impulsos y sentimientos. Para Brenna ${ }^{5}$, Freud ${ }^{6}$ opina en su teoría de la feminidad que la fuerza de cualquier tipo de afecto, ya sea ira, envidia, amor u odio, supondrá la base para el nivel económico de organización psíquica. Este orden psíquico era uno de los elementos a los que se refirió Freud ${ }^{7}$ dentro de su teoría de los niveles de organización psíquica. Además del nivel económico, se encontraban el nivel topográfico, y

4. Ibídem

5. BRENNA,Teresa. Interpretation of the Flesh: Freud's Theory of Feminity. London, Routledge 1992.

6. FREUd, S. Tres ensayos sobre la teoría sexual. Madrid, Alianza Editorial 1972.

7. FreUd, S. La interpretación de los sueños. Barcelona, Planeta -De Agostini 1985. 
el dinámico. En el diseño de esta teoría, Freud atendería a la hipótesis de lo físico, los procesos de la energía psíquica, y la confabulación de la carne. A pesar de que no ha sido una teoría especialmente bienvenida, para Brenna ${ }^{8}$, era la única que podía acercarnos a la solución del misterio de la feminidad. Pero centrémonos en las vertientes de lo físico y la conspiración de la carne en lo femenino. Según Brenna ${ }^{9}$, Freud sostiene que todo aquello que nos hace cambiar una idea, un pensamiento, de alguna forma se refleja físicamente. Todo aquello que envuelve a las emociones se ve reflejado en lo físico, ya se externa o internamente.

Neumann afirma lo siguiente, refiriéndose a la constitución de la principal manifestación del arquetipo: «Como condición a priori, los arquetipos representan el caso psíquico especializado del pattern of behaviour familiar para el biólogo que confiere su naturaleza específica a todos los organismos vivos» ${ }^{10}$. Es a partir de ahí cuando el arquetipo opera para con el individuo en un carácter compulsivo, que además está conducido por un mecanismo emocional, como es el caso que concierne a la novela que se está analizando. $\mathrm{Al}$ respecto de la demarcación de un arquetipo, este se ve también vinculado a una intensa agitación bio-psíquica. Sin duda, aflora a través de un carácter con tintes impulsivos, así como desde el punto de vista del instinto, con la afectividad, en la que un arquetipo domine la personalidad sobre la que opera.

La influencia del arquetipo va más allá de su ejecución inconsciente. Su persistencia debe tenerse en cuenta, ya que permanece como una disposición auto-exhortativa inconsciente de la personalidad que influye en el humor, en las ideologías de ésta, así como en sus intereses, y en su consciencia. Es importante mencionar lo dicho por Neumann ${ }^{11}$ referente a la vinculación de estos con los estados psicóticos, algo en lo que no nos detendremos, pero que debemos tener en consideración para la perspectiva desde la que hay que entender el análisis de esta novela. Sobre todo, fijando nuestra atención en esta perspectiva, a propósito de Mrs. White, y, por ende, en la influencia ${ }^{12}$ que ejerce sobre su hija, a partir de lo dicho.

El arquetipo puede aparecer en muchas ocasiones estableciendo la situación actual que se está viviendo. En otras palabras y de acuerdo con

8. BRENNA,Teresa. Op. cit., p. 5.

9. Ibídem.

10. Neumann, Erich. Op. cit., p. 20.

11. Ibíd., pp. 19-34.

12. Expondremos a lo largo de nuestro análisis, cómo el entorno familiar visto a través del arquetipo de la Gran Madre, y por ende del Gran Femenino, es el origen del bullying que sufre Carrie. 
Neumann ${ }^{13}$, la manifestación del arquetipo como la forma simbólica que tiene de expresarse el inconsciente.

Neumann ${ }^{14}$ afirma que todos los contenidos del inconsciente se expresan como femeninos. Lo inconsciente da cabida también a todo tipo de complejos, instintos y arquetipos tanto de género masculino como femenino. Por lo tanto, la opacidad, en relación a la consciencia, que subyace en lo inconsciente hará sus manifestaciones a través de lo femenino. Así pues, veamos dichas manifestaciones.

La denominada Madre Terrible, en términos del arquetipo, tal y como Neumann ${ }^{15}$ denominaría el lado negativo de la feminidad, que adquiere la gran mayoría de sus imágenes del carácter negativo, manifestadas a través de iconos generados en las diferentes formas de arte. No obstante, este lado más oscuro, sinónimo de muerte, abismo, necesidad de víveres, peligro, y desamparo, no es el único. El lado femenino más amable, según Neumann ${ }^{16}$, administra calor, da vida, alimento y amparo, algo que quizás vemos más relacionado con lo materno. Así que nos encontramos con una mujer que por un lado da vida y por otro la arrebata.

Neumann ${ }^{17}$ utiliza un diagrama distinto para probar la división de la feminidad en dos caracteres: el elemental (M) catalogada como lo maternal y el transformador (A), catalogada como el ánima. Aunque realmente no estamos interesados en subrayar el carácter positivo de ambos, diremos, para que el lector vea con más claridad, que el personaje de la madre que aquí nos ocupa se encuentra lejos del mismo, mientras que sobresale el aspecto más negativo. Es importante, sin embargo, señalar que ambos caracteres pueden operar al mismo tiempo. Es más, a priori, el carácter transformador está dentro del elemental, ya que es inherente a la naturaleza, pero es el más fuerte, el que finalmente destacará sobre el segundo. En rasgos generales, el carácter elemental operará donde la armonía resida como si de un status quo se tratara. En relación al carácter transformador ocurre todo lo contrario: este se decanta más por el lado de la transformación, el dinamismo y el desarrollo.

Así pues, el carácter elemental, al igual que el transformador, se divide en dos caras, la positiva y la negativa. El carácter elemental (M) en general representa el lado más conservador de la psique. El carácter elemental positivo $\left(\mathrm{M}_{+}\right)$destaca las características de una figura maternal más bondadosa,

13. NeUmann, Erich. Op. cit., pp. 19-34.

14. Ibíd., pp. 34-39.

15. Ibid., pp. 39-52.

16. Ibídem.

17. Ibíd., pp. 101-319. 
que nutre, da vida y cobijo. Es normalmente un personaje muy bello, que está relacionado con los colores de la tierra y la vegetación. El carácter elemental negativo (M-) encuentra su origen, según Neumann, en la Madre Terrible, o la Vieja Bruja: «en la experiencia interna, y la angustia, el espanto y el temor a la amenaza implicada por el Gran Femenino» ${ }^{18}$. El carácter elemental negativo (M-) es asociado con los colores rojo y negro, así como con toda la imaginería de la muerte. Dichas representaciones del arquetipo (M-) son de aspecto tenebroso y en definitivita el objetivo es destruir mediante su carácter opresivo.

Por otro lado, tendríamos el carácter transformador (A), también con dos caras. De acuerdo con Neumann ${ }^{19}$, este se separa del carácter elemental adquiriendo su propia autenticidad. El aspecto más simbólico de este carácter se erige en relación a todos los misterios que se dan dentro del cuerpo de la mujer: menstruación, embarazo, alumbramiento o lactancia. A menudo instigan cambios positivos o negativos. Su actuación para con quienes la proyectan es indirecta. Por un lado, su vertiente más positiva (A+) está inspirada en figuras virginales, que ayudan, bien mediante la atracción sexual, bien mediante la inspiración. Los colores asociados a esta figura son la gama de los tonos pastel. Son inocentes y naturales, así como de una belleza delicada. Por último, encontramos la feminidad en su versión del carácter transformador negativo figurada en una Seductora, o Joven Bruja (A-). Su objetivo es extenuar al personaje mediante la seducción, hechizos o la tentación. Es relacionada con colores vivos, sobretodo el rojo y el negro. Destaca por su belleza sensual e impactante.

\section{Análisis}

La moralidad de los valores en su aspecto más negativo y positivo ha sido transmitida a la literatura a través del folclore y la mitología. La maldad está ligada en muchas de sus formas a la tragedia. Según el autor, la maldad se ha visto infundida por la religión con intenciones retóricas (Reinado del Mal) y estéticas (penumbra, tinieblas, terror) ${ }^{20}$. La primera idea de la maldad aunada al pecado es introducida por el Cristianismo, causada por la desobediencia y la ofensa a Dios por Eva en el Edén, por la que se vería castigada la humanidad. En la simbología más cristiana, como detalle a tener en cuenta, el cuervo

18. Ibíd., p. 153.

19. Ibíd., pp. 211-319.

20. PAULSON, Ronald. Sin and Evil: Moral values in Literature. New Haven \& London, Yale University Press, 2007. 
guía a Eva, y de ahí que esta solo nos guíe por las tinieblas. En su versión opuesta, encontraríamos la paloma, que guía hacía la luz. Pero hasta ahora, hemos mostrado el Mal, con mayúscula, referido al pecado, como una creación mitológica por parte del cristianismo que lo explica, y en la que observamos referencias en la novela:

And God made Eve from the rib of Adam. 'And Eve was weak and loosed the raven on the world...' (and the raven was called Sin, and the first Sin was Intercourse. And the Lord visited Eve with a Curse, and the Curse was the Curse of Blood. And Adam and Eve were driven out of the Garden and into the World and Eve found than her belly had grown big with a child ${ }^{21}$.

El otro concepto de maldad se refiere a la idea de dañar, infligir sufrimiento a otros. La abominación y la corrupción son términos inherentes a la definición de maldad. El primero recoge todo tipo de blasfemia, mientras que el segundo está relacionado con la pertenencia a un extremo que define en cualquiera de sus vertientes a los opuestos por excelencia: el bien y el mal (ej; espíritu vs. Carne, Luz vs. Oscuridad). En el Nuevo Testamento, el dominio de Dios sobre el mal desapareció, y tal y como estaba constituido en el Antiguo Testamento, ahora tenía su propio campo de acción. El término Satán aparecería entonces para designar a su oponente. La mayor actuación sobre el hombre por parte de Satán se resume en los Siete Pecados Capitales, y por otro lado, en las brujas, y hechiceros, personas con poderes diabólicos que forman parte del séquito del mal. A partir de aquí, numerosas formas de expresión del mal se han dado de mano del folclore y de la mitología, bien con representaciones simbólicas, bien alegóricas. Y es en la mitología dónde la mujer tendría su papel estrella, sobre todo si este está deformado una vez más por la religión. Así pues, la maldad es vista por Mrs. White, no solo en las mujeres como las pecadoras por defecto, sino por las hacedoras de pecados:

And there was a second Curse, and this was the Curse of Childbearing, and Eve brought forth Cain in sweat and blood... And following Cain, Eve gave birth to Abel, having not yet repented of the Sin of Intercourse. And so the Lord visited Eve with a third Curse, and this was the Curse of Murder...And still Eve did not repent, nor all the daughters of Eve, and upon Eve did the Crafty Serpent found a kingdom of whoredoms and pestilences ${ }^{22}$.

De acuerdo con Bennardo ${ }^{23}$, el cristianismo provocó en la sociedad una psicosis hacia el sexo, desencadenando una aversión neurótica que rozaba la

21. KING, Stephen. Op. cit., pp. 345-346.

22. Ibíd., pp. 345-346.

23. Di BENNARDo, Filippo Giuseppe. La insurrección de Lilith. Sevilla, Arcibel, 2009. 
represión. El miedo desatado por alcanzar el ideal místico estimuló una visión del cuerpo y de la sexualidad, motivando resultados negativos para la mujer ${ }^{24}$. Esta lucha entre la carne y el espíritu hizo que se sustituyera la carne por lo femenino, haciendo que los males fueran sinónimo de feminidad. De ahí su identificación con el demonio y, por lo tanto, con su carácter negativo. Sin duda, este concepto de la feminidad ocasionó que la mujer personificara la tentación que empuja al hombre a la perversión del sexo. No obstante, los tres arquetipos por excelencia que han definido a la mujer giran en torno a lo sexual: «como virgen (caracterizado por la ausencia de sexualidad), como esposa y madre (que representa la sexualidad con un varón, con el marido) y como prostituta (donde la sexualidad femenina se manifiesta con varios hombres) $»^{25}$.

Allí donde la transformación de la materia con más claridad se denota es en la transformación alquímica de la personalidad humana. Pero mucho antes de aparecer en los misterios como una experiencia anímica y personal, se vive en su proyección en la naturaleza animada. Por ello hay una gran cantidad de símbolos de la transformación espiritual del reino natural que se componen de símbolos más misteriosos. De ahí que se dé la relación entre la simbología de lo somático y del recipiente, relacionados con el Gran Femenino donde se da la simbología más abstracta del carácter matriarcal. Dentro de su simbología, al igual que la sangre se transforma en leche, como derivación del nacimiento, como obra de creación por parte del Gran Femenino; el elixir de la vida conserva su simbología natural y se manifiesta en los símbolos de la planta o del fruto de la inmortalidad, de la flor o de la pepita, y además, según demostraremos más adelante, de la sangre como fruto de la vida ${ }^{26}$.

La violencia entre pares suele ser resultado de las relaciones entre los agresores y sus respectivos entornos de desarrollo tales como el social, el cultural o el familiar. Entre estos contextos queremos destacar la relación que existe también entre la víctima de bullying, el entorno familiar y el social. En ocasiones, debido al bagaje familiar ${ }^{27}$, la percepción social como individuo no es

24. El entorno familiar de Carrie basado en el fundamentalismo cristiano será el causante de su inadaptación social. Las creencias de la mujer como encarnación del mal, en todos los aspectos inherentes al género, serán el eje principal en el que la madre de la protagonista basa sus creencias, y que por supuesto impondrá a Carrie.

25. Di BENNARDO, Filippo Giuseppe. Op. cit., p. 46.

26. NeUmann, Erich. Op. cit., p. 30.

27. El entorno familiar de Carrie está compuesto únicamente por su madre. Este se basa en las enseñanzas dictadas por el fundamentalismo cristiano, fe en la que se refugió Mrs. White, tras una mala experiencia sentimental con el padre de Carrie. Dicha experiencia la afecto de tal forma que trastocó su concepto de la feminidad, pasando a ser 
aceptada, siendo entonces cuando se puede convertir en víctima de bullying ${ }^{28}$. Además, de acuerdo con Arroyave ${ }^{29}$, la adolescencia es un período en el cual la probabilidad de sufrir estas agresiones es mayor.

El arquetipo del Gran Femenino en su carácter negativo efectivamente devora y aborrece lo que forma parte de su esencia como tal. En el caso que nos ocupa, Mrs. White ${ }^{30}$ rechaza la propia naturaleza de su hija, algo inherente también a ella, en ambos sentidos. Por ello, nuestra idea es la de ofrecer la perspectiva del arquetipo de la Gran Madre como causa en las agresiones de bullying:

'O Lord,' Momma declaimed hugely, her head thrown back, 'help this sinning woman beside me here see the sin of her days and ways. Show her that if she had remained sinless the Curse of Blood never would have come on her ${ }^{31}$.

El apoyo social se inicia antes del nacimiento, y con el tiempo se consolida mediante las interacciones con la familia, y es partiendo de estas interacciones, que se extiende al entorno social ${ }^{32}$. De acuerdo con Neumann ${ }^{33}$, la primera experiencia que tiene el niño de la madre es la Gran Madre, después vendrá el conocimiento objetivo de su madre. Stephen King presenta a Carrie como una dependiente absoluta de su madre, a pesar de todo lo que supone, King hace uso de este arquetipo en su estadio originario: «la realidad de un todopoderoso ser femenino numinoso del que depende por entero» ${ }^{34}$. Podemos observar cómo Carrie, incluso al ser castigada y vapuleada por su madre, simplemente por ser mujer, le pide socorro para que le cuente qué pasa, no habiendo más explicación que la necesidad por naturaleza de lo materno, a pesar de que intente destruirnos, ya que forma parte de ello:

concebida, desde entonces, como único exponente de la maldad y la lascivia. Enseñanza que impone a su hija en un ambiente familiar austero, violento y delirante.

28. VÁldÉS, A. y MARTínEZ, E. A. «Relación entre el autoconcepto social, el clima familiar y el clima escolar con el bullying en estudiantes de secundaria». Avances en Psicología Latinoamericana 32 (2014), pp. 447-457.

29. Arroyave, Pilar. «Factores de vulnerabilidad y riesgo asociados al bullying». Revista CES Psicología 5 (2012), pp. 118-125.

30. Tal y como iremos observando a lo largo del análisis, la figura de Mrs. White en su proyección del arquetipo de la Gran Madre, en el carácter negativo, se va desvelando como origen del acoso al que se ve sometida su hija. Nos centraremos en un entorno familiar desestructurado y represivo, cuyo impacto en la psique de la joven, va destapando la influencia del arquetipo de la Gran Madre como causante del bullying.

31. KING, Stephen. Op. cit., p. 346.

32. ORCASITA, L. y URIBE, A. «La importancia del apoyo social en el bienestar de los adolescentes». Psychologia: avances de la disciplina 4 (2010), pp. 69-82.

33. NEUmanN, Erich. Op. cit., p. 30.

34. Ibíd., p. 30. 
Momma's magnified eyes swam in front of her.

'You spawn of the devil,' she whispered.

'Why was I so cursed?

Tal y como indica Neumann, la dinámica del arquetipo ${ }^{36}$ revela la influencia manifestada mediante emociones positivas y negativas. En el caso de emociones negativas, del arquetipo de la Gran Madre, encontramos la idea de que el yo pueda ser subyugado ${ }^{37}$. Estos estados pueden sobrevenir mediante estados maníacos. Dichos estados se ven reflejados de forma inconsciente además de apoderarse de la consciencia. En el caso de Carrie, la hija, como víctima de la influencia de su madre, se convierte en el objetivo de estos estados maníacos proporcionados por la influencia de su madre.

Así pues, podemos observar la importancia del funcionamiento del núcleo familiar en la etapa adolescente, y por ende, en la estructura del apoyo social debido a la cantidad de cambios a los que se ve sometido el individuo ${ }^{38}$.

Mrs. White está atormentada por el fundamentalismo y hace que las manifestaciones de esta autoridad, en términos religiosos, avasallen en su figura maternal a su hija con un peso demoledor en la psique de la última. Veamos un ejemplo de la desfigurada visión de lo femenino que tiene Carrie, tal y como hemos mencionado anteriormente, propiciado por el concepto que su madre le ha transmitido de lo femenino. Concepto que le impedirá su propio desarrollo como mujer y que propiciará que sea objeto del rechazo de su propio género en forma de bullying:

She was wearing a little yellow dress, sort of cute but awfully long for a little girl in the summer. It came down to her shins.

'She didn't smile back. She just pointed and said, «What are those?»

'I looked down and saw that my top had slipped while I was asleep. So I fixed it and said, "Those are my breasts, Carrie».

'The she said-very solemnly: «I wish I had some».

'I said: «you have to wait, Carrie...

'No, I won't», she said. «Momma says good girls don't» She looked strange for a little girl, half sad and half self-righteous.... «Well, I'm a good girl. And doesn't your mother have breasts?»...

35. KING, Stephen. Op. cit., p. 347.

36. Nuestro objetivo es exponer la influencia que tiene el carácter negativo del arquetipo de la Gran Madre (proyectado en Mrs. White) en la inadaptación social de Carrie, como muestra de la influencia de la faceta más negativa del arquetipo.

37. NeUmann, Erich. Op. cit., p. 19.

38. Fernanda U. Ana; OrCasita T. Linda y Aguillón G. Erika. «Bullying, redes de apoyo social y funcionamiento familiar en adolescentes de una institución educativa de Santander, Colombia». Psychologia: Avances de la disciplina 6 (2012), pp. 83-99. 
'She lowered her head and said something so softly I couldn't hear it...She called them dirtypillows, as if it was all one word ${ }^{39}$.

En el caso que nos ocupa de dos mujeres tan diferentes, como iguales, el concepto de la maternidad y la feminidad es visto desde dos perspectivas bien distintas, incluso por ellas. Pero centrémonos en el significado del arquetipo en sí, y lo que puede hacer en nosotros ${ }^{40}$.

De acuerdo con Herrera ${ }^{41}$, el criterio bajo el que el núcleo familiar debe funcionar está directamente relacionado con la finalidad de impulsar el desarrollo pleno de sus miembros de forma satisfactoria. Es por ello curioso que toda la vorágine que se crea en la vida de Carrie se desate a la vez que la menstruación ${ }^{42}$ aparece en su vida por primera vez. El motivo de destacarlo se debe a la correlación entre menstruación, la llegada de la misma en el período adolescente, y el entorno familiar, en relación a la ocultación. Elementos que hacen que Carrie sea, una vez más, víctima de las agresiones de sus compañeras: «Momma closed the door behind her. 'You're a woman', she said softly... 'Why didn't you tell me?' I was so scared! And the girls all made fun and threw me things and-'» ${ }^{43}$.

De acuerdo con Horney ${ }^{44}$, es necesario prestar atención a las perturbaciones que se relacionan con los días antes de la llegada del flujo menstrual. A la vez, este proceso sintomático se ve, indudable e irremediablemente ligado a otros de irritabilidad, o de carácter depresivo. Eso sí, esto no quiere decir, de acuerdo con Horney ${ }^{45}$, que esté relacionado con perturbaciones de índole psicológica o histérica, como es el caso que nos ocupa. No debemos olvidar, comenta Horney ${ }^{46}$, que una vez el flujo menstrual ha hecho su aparición, esta sintomatología desaparece.

39. KING, Stephen. Op. cit., p. 334.

40. La proyección del arquetipo de la Gran Madre en Carrie se entiende a partir de la correspondencia entre el período de la adolescencia (cuando Carrie es víctima del bullying), el ambiente familiar y el desarrollo psicológico de la adolescente. Es entonces cuando vemos cómo la influencia del arquetipo tiene consecuencias negativas.

41. Herrera, P. M. «La familia funcional y disfuncional, un indicador de salud». Revista Cubana de Medicina Integral 13 (1997), pp. 1-4.

42. Una de las situaciones de bullying que sufre Carrie se relata al comienzo de la novela, con la llegada de su primera menstruación. Ante una situación inesperada y desconocida para la joven, lejos de ser comprendida, se convierte de nuevo en blanco de las risas e insultos de sus compañeras en una situación de humillación provocada por el desconocimiento de su cuerpo.

43. KING, Stephen. Op. cit., p. 346.

44. Horney, Karen. Psicología Femenina. Madrid, Alianza Editorial, 1977.

45. Ibíd., pp. 111-121.

46. Ibídem. 
Si atendemos al hilo de la novela que nos ocupa, la idea de que Carrie haya tenido su primera menstruación está directamente ligada a su vez, con lo que Horney ${ }^{47}$ denomina conflictos vinculados con el deseo de ser madre. Es decir, si comparamos todo lo dicho anteriormente, en paralelo con el arquetipo de la Gran Madre, nos toparíamos con el carácter elemental de la madre (M). Enfrentado simbólicamente a madre e hija, tendríamos el carácter elemental positivo $\left(\mathrm{M}_{+}\right)$proyectado en Carrie, de acuerdo a su madre, ya que Carrie aunque no sepa que lo es, tampoco lo ve como nada negativo. Sin embargo, su madre se proyecta definitivamente en Carrie como el carácter elemental negativo (M-). Por un lado, se debe a que su madre, una vez su hija está sucumbiendo al lado más negativo de la mujer, rechaza (devora) a lo que ella una vez le dio vida. Esto además es perfectamente lógico, ya que estos caracteres también se relacionan con la idea que tiene la feminidad de sí misma. Es decir, lo que proyecta Carrie de sí misma al tener la menstruación por ser hacedora de vida y, como hija, frente a lo que rechaza su madre. Ambas proyectan lo que la otra niega o rechaza. Carrie rechaza a su madre (M-) y su madre $(\mathrm{M}-)$ rechaza a su hija $\left(\mathrm{M}_{+}\right)$, nueva fuente de vida, lo que para su madre es sinónimo de pecado y de algo a devorar.

Es necesario entonces continuar hablando de la perturbación que ha podido desencadenar en Carrie la llegada de la menstruación. Basándonos en las teorías de Horney ${ }^{48}$, la aparición del flujo desemboca en impulsos violentos, así como en fantasías, sentimientos depresivos o falta de energía, lo que produce una opresión tal que acabe siendo la causa de ciertas perturbaciones..

La perturbación que se crea en Carrie puede estar relacionada con una parte más psíquica. Su desasosiego va más allá, ya que llega incluso a tambalear su visión de lo femenino. Por ello que se crea el enfrentamiento con su madre. Ahora, siendo Carrie consciente de su papel en la feminidad, se da cuenta de que lejos de ser algo negativo, tiene ahora la capacidad de ser portadora de vida $\left(\mathrm{M}_{+}\right)$. El conflicto, si cabe, aún es mayor cuando tiene que enfrentarse con la que una vez le dio vida $\left(\mathrm{M}_{+}\right)$, y que es ahora la que también quiere aniquilarla $(\mathrm{M}-)$. Aniquilación que la madre muestra desde el principio invalidando la capacidad de su hija de relacionarse socialmente, para más tarde, contaminar el empeño por parte de Carrie de integrarse en su entorno social. Mrs. White no cesará en su empeño de aniquilar cualquier muestra de lo femenino, con charlas delirantes como la relacionada con la menstruación:

47. Ibíd., pp. 206-207.

48. Ibíd., pp. 111-121.

Feminismo/s 25, junio 2015, pp. 183-200 
And Eve was weak and loosed the raven on the world,' Momma continued,' (and the raven was called Sin, and the first sin was Intercourse. And the Lord visited Eve with a Curse, and the Curse was the Curse of Blood...And there was a second Curse, and this was the Curse of Childbearing, and Eve brought forth Cain in sweat and blood... Now Momma dragged her, half-standing and half-crawling, down to the altar, where both fell on their knees. ${ }^{49}$

La madre de Carrie (M-) deja de ser un ejemplo para ella cuando su profesora de gimnasia, Miss Desjardin ${ }^{50}(\mathrm{~A}+)$, aparece proyectándose como carácter transformador positivo, dándole todo lo que su madre (M-) pretende devorar. En la medida de lo posible, Miss Desjardin le dará protección frente al acoso escolar al que se ve sometida. Veamos uno de los ejemplos donde Miss Desjardin acude en su ayuda con la llegada de la menstruación:

'It hurts,' Carrie goarned. 'My stomach...'

'That passes,' Miss Desjardin said. Pity and Self-shame met in her and mixed uneasily. ... She took one of the sanitary napkins from the broken dispenser and unwrapped it.

'Look,' she said. 'Like this' ${ }^{51}$.

Sin duda, una forma de ponerle el broche final al lado más despiadado de la figura de la Gran Madre, desde la perspectiva del que debe vivir bajo su cobijo, es el poema que Carrie escribió para el colegio, el cual denotaba desesperación por doquier. Recoge la versión más oscura del Gran Femenino. Es su versión M- (Madre Terrible). El poema demuestra cómo Carrie no entiende, cómo no encuentra protección, ni por parte de Dios ni de su madre, los cuales tendrían el deber de hacerlo. De acuerdo a la metodología de la interpretación que hemos seguido, Carrie se pregunta ¿qué sigue haciendo mal, si hace lo que su madre le ordena? Instintivamente, sabe que algo falla en toda esta ecuación, ya que la realidad bajo la que le han hecho vivir no le hace sentirse a salvo. En definitiva, Carrie está destinada a crecer y morir en una serie de incoherencias que, una vez llegada la adolescencia, no entiende y sin duda, rechaza, aunque la fuerza del Gran Femenino es tan poderosa que hará que perezca bajo las mismas llamas que consumen a su madre, en un sentido real y metafórico, y devorada por aquella que un día le dio la vida.

49. KING, Stephen. Op. cit., pp. 345-346.

50. Miss Desjardin refleja el carácter positivo del arquetipo de la Gran Madre. La profesora intenta protegerla frente al acoso. A pesar de la brevedad de su aparición, ésta merece ser destacada para señalar el fuerte contraste con Mrs. White, en la versión contraria del arquetipo. Sin duda la reacción de Carrie ante la proyección del arquetipo en su carácter transformador positivo $(\mathrm{A}+)$, queda reflejada en la cita.

51. KING, Stephen. Op. cit., p. 325. 
Jesus watches from the wall,

But his face is cold as stone,

And if the loves me

As she tells me

Why do I feel so all alone ${ }^{52}$ ?

Y como en el mayor de los enfrentamientos entre los caracteres positivo y negativo de la feminidad, ambas se destruyen y se autodestruyen. Carrie se convertirá finalmente en $\mathrm{M}-$, ya que destruirá su entorno familiar y social, como su madre lo ha hecho con ella: «I came to kill you, Momma. And you were waiting here to kill me» ${ }^{53}$.

La maternidad desde la perspectiva de la madre de Carrie fue, y finalmente sigue siendo vista como un castigo de Dios, y es por ello, que se ve en el derecho de devorar a lo que una vez dio vida (M-):

'The Lord Works in mysterious ways His wonders to perform. I see that now. When the pains began I went and got a knife-this knife' she held it up- and waited for you to come so I could make my sacrifice. But I was weak and backsliding. I took this knife in hand again when you were three, and I backslid again. So now the devil has come home.' She held the knife up, and her eyes fastened hypnotically on the glittering hook of its blade ${ }^{54}$.

\section{Conclusión}

Los arquetipos, como en este caso, a partir del Gran Femenino, nos hacen llegar modelos desde una de las ópticas de la feminidad. Por otro lado, también se demuestra cómo estos arquetipos que se dan en la feminidad llegan a actuar incluso de forma negativa con su mismo género si cabe.

Este estudio sobre las dos protagonistas principales femeninas, a través del arquetipo del Gran Femenino, es de nuevo un paso más en el estudio y actuación del inconsciente colectivo y del arquetipo del Gran Femenino que sigue actuando a través de los diferentes estereotipos que se aún se dan en la literatura más contemporánea. Stephen King, según nuestro estudio, deja claras dos versiones antagónicas de la feminidad, ambas en su versión más voraz y con unas consecuencias nefastas en su vida. Por un lado, la que podríamos denominar la más feminista, que exige una denuncia al control y la depravación a la que se ha visto sometida la mujer. Mientras que, por otro lado, en el personaje de Mrs. White sólo podemos reconocer el lado más ancestral de la mujer, que a su vez tiene que luchar por mantener el lado más conservador

52. KING, Stephen. Op. cit., p. 354.

53. Ibid., p. 421.

54. Ibídem.

Feminismo/s 25, junio 2015, pp. 183-200 
de la feminidad, siendo por ello el origen del bullying al que se ve sometida su hija. Esta lucha se lleva a cabo de forma interna y externa (ámbito familiar y escolar), teniendo por ello consecuencias en la socialización de su hija. Es por ello que para Mrs. White el único objetivo será devorar y aniquilar todo aquello que opere en contra de la versión más conservadora de la feminidad, impidiendo $0^{55}$ cualquier otra versión lo femenino. Es imposible para ella aceptar a una mujer con pretensiones fuera de los severos dictados del fundamentalismo cristiano, siendo estos dictados los únicos bajo los que crecerá Carrie. Tal es así, que el arquetipo de Carrie actúa en su madre como un contraste con la realidad que Carrie empieza a vislumbrar entre sus compañeras de instituto y, que como si de una gran metáfora se tratase, esta realidad se provoca con la llegada de la menstruación.

El cambio en su paso de niña a mujer no se produce sólo fisiológicamente, sino también psicológicamente, sobre todo ligando esta evolución al entorno social, contrario al que Mrs. White le somete. Es entonces cuando Carrie se rebela contra su madre, tras el rechazo de su entorno escolar que, si cabe aún más, se vuelve más severo, justo cuando llega la menstruación. La joven se replantea lo establecido en su inconsciente y que tanto ha sido obligada a reprimir, luchando contra el contraste de la realidad que conoce. Mrs. White no consigue ni siquiera a través de Carrie aceptar la transformación en su proceso de individuación, que la liberaría a su vez de tanta represión y censura. Así pues, a medida que su hija va creciendo, el ambiente familiar al que Mrs. White somete a su hija se va endureciendo. Ejemplo de ello sería el paso de niña a mujer, con la llegada de la menstruación, donde las relaciones con $\operatorname{chicos}^{56}$ van teniendo cabida en la vida de Carrie.

Exponiendo estas similitudes, podríamos encajar a los personajes, de forma más gráfica, en el esquema que se propone del arquetipo del Gran Femenino en la totalidad de la obra, antes de su análisis. De forma general, observamos una variante importante en torno a la protagonista, Carrie, y

55. Mrs. White es el origen de la situación de Carrie, ya que en el seguimiento literal de sus convicciones, impide que la joven se desarrolle socialmente. Carrie no tiene más remedio que someterse a los dictados de su madre, porque de lo contrario, también se verá sometida a un acoso en el ambiente familiar aún mayor. Por ello, el hecho de que Carrie sea una chica con verdaderas carencias para con la gestión de las relaciones sociales y sentimentales, la convierte en presa fácil del bullying.

56. De nuevo observamos el motivo por el cual Mrs. White es la causa del bullying al que se ve sometida Carrie. Mrs. White, como indicamos anteriormente, proyectará en su hija, regida por sus convicciones religiosas, la visión que tiene de los hombres y las relaciones sexuales. Un ejemplo más de la educación a la que Mrs. White somete a Carrie y que se proyecta en el entorno escolar como víctima de bullying. 
todas las mujeres que forman parte de su vida. Por un lado, su madre, Mrs. White, encaja dentro del carácter del Gran femenino como Madre Bondadosa $(\mathrm{M}+)$, ya que su única intención es proteger a su hija, al fin y al cabo, de lo que ella cree que es malo, no siendo realmente consciente de que es la única que provoca que su hija sea víctima de su entorno social. Por otra parte, la versión más llamativa es su faceta de Madre Terrible (M-), algo que quizás explota con más vehemencia. De acuerdo con nuestro estudio, su visión de la vida, la religión, hace ser una madre devastadora con su hija impidiendo que ésta crezca en un ambiente familiar equilibrado fomentando así que sea víctima del bullying. Por otro lado, Carrie tiene que luchar con lo que le rodea, que dista bastante del entorno al que la somete su madre; entorno que no la acepta tampoco. El carácter transformador de lo femenino se proyecta en sus dos versiones. De esta forma, el resto de personajes femeninos que componen el elenco quedarían englobados, por un lado, en el carácter transformador negativo (A-) y por el otro, en el carácter elemental positivo (A+). En el primero se puede englobar todo aquello de lo que su madre quiere mantener lejos a Carrie, que es la feminidad en su estado puro y que va desde sus compañeras de instituto hasta, quizás, la profesora Miss Desjardin, quien representa en su estado máximo la feminidad. Estas mujeres que forman parte de la vida de Carrie ejercen su influencia arquetípica en el carácter elemental positivo $(\mathrm{A}+)$. Ellas proyectan lo que Carrie, lejos del fanatismo que la azota diariamente, ve y entiende como normal. Ellas, que rechazan este fanatismo en el concepto de lo femenino, y que Carrie representa, lo expresan mediante la violencia en forma de bullying contra todo lo que Carrie proyecta. La actitud del entorno femenino, fuera de su casa, representa para Carrie una mezcla entre el carácter elemental positivo (A+), y carácter transformador negativo (A-). Vistos desde el A+, las compañeras de clase de Carrie, y la profesora Miss Desjardin le dan la posibilidad de ver que existe algo más allá del los dictados fundamentalistas de su progenitora. Sin embargo, las tácticas usadas por las mismas representan la parte más negativa de la feminidad, ya que el bullying que sufre pide una transformación en Carrie por no encajar en la sociedad adolescente, es una visión transformadora, pero negativa, de la feminidad. La base de este argumento reside en la idea de que todo aquello que la feminidad, es decir, el entorno escolar de Carrie, no vaya a tolerar, será devorado y aniquilado, en este caso, en forma de bullying hacia ella, coincidiendo de nuevo con el comportamiento del carácter transformador negativo de la feminidad (A-).

Esta situación otra vez escribirá el final de Carrie, marcado por la violencia entre seres del mismo género. Nos encontramos con que Carrie, a pesar de estar rodeada por ambos caracteres de lo femenino e incluso sabiendo, 
en algún punto de su vida, que lo que te da la vida no debe quitártela, elige finalmente irse entre las llamas con la que le dio la vida. Y de esta forma tan fatídica, hemos analizado la raíz de la influencia del inconsciente, en su forma del carácter negativo de la Gran Madre, y que acaba devorando a Carrie, no sin que antes destruyera todo el entorno social que tampoco la aceptó.

\section{Referencias bibliográficas}

ARROYAVE, Pilar. «Factores de vulnerabilidad y riesgo asociados al bullying». Revista CES Psicología 5 (2012), pp. 118-125.

BRENnA, Teresa. Interpretation of the Flesh: Freud's Theory of Feminity. London, Routledge, 1992.

FERnANDA U. Ana; OrCASitA T. Linda y Aguillón G. Erika. «Bullying, redes de apoyo social y funcionamiento familiar en adolescentes de una institución educativa de Santander, Colombia». Psychologia: Avances de la disciplina 6 (2012), pp. 83-99.

FreUd, S. La interpretación de los sueños. Barcelona, Planeta-De Agostini, 1985.

FREUD, S. Tres ensayos sobre la teoría sexual. Madrid, Alianza Editorial, 1972.

HERRERA, P. M. «La familia funcional y disfuncional, un indicador de salud». Revista Cubana de Medicina Integral 13 (1997), pp. 1-4.

Horney, Karen. Psicología Femenina. Madrid, Alianza Editorial, 1977.

KING, Stephen. "Carrie», en The Shining, Carrie and Misery. Great Britain, Chancelor Press, 1993, pp. 319-439.

Neumann, Erich. La Gran Madre: Una fenomenología de las creencias femeninas de lo inconsciente. Madrid, Editorial Trotta, 2009.

OrCASITA, L. y URIBE, A. «La importancia del apoyo social en el bienestar de los adolescentes». Psychologia: avances de la disciplina 4 (2010), pp. 69-82.

OrTIZ-OSÉS, Andrés. Arquetipos y Sentido. Bilbao, Universidad de Deusto, 1988.

PAULSON, Ronald. Sin and Evil: Moral values in Literature. New Haven \& London, Yale University Press, 2007.

VAldÉS, A. y MARTínez, E. A. «Relación entre el autoconcepto social, el clima familiar y el clima escolar con el bullying en estudiantes de secundaria». Avances en Psicología Latinoamericana 32 (2014), pp. 447-457. 